\title{
ALLUVIAL DIAMONDS FROM THE RIO SORISO (JUINA, BRAZIL)
}

\author{
Patrick Hayman $^{1}$, Maya Kopylova ${ }^{1}$ and Felix Kaminsky ${ }^{2}$ \\ ${ }^{1}$ University of British Columbia, Vancouver, Canada $;{ }^{2}$ KM Diamond Exploration Ltd., Vancouver, Canada
}

\section{INTRODUCTION:}

Sixty nine diamonds recovered from the Rio Soriso, Juina area, Brazil, are characterized by morphology, colour, fluorescence, cathodoluminescence, surface features, nitrogen content and aggregation, and relative concentration of platelets.

The Juina area is located in Mato Grosso state of Brazil (Fig. 1, inset) and is situated near the southwestern edge of the Amazonian craton. The area contains several river valleys with diamondiferous alluvial deposits. Kimberlites have been discovered in the area but to date none have proven economic. Diamonds analyzed from these pipes posses a different 'fingerprint' than alluvial diamonds recovered. The Rio Soriso is a small tributary which feeds into the Rio Porcao (Fig. 1). This study determines typomorphic features of the Rio Soriso diamonds and constrains diamond-forming processes below the Amazonian cratons which may in turn have application towards locating the source in the future.

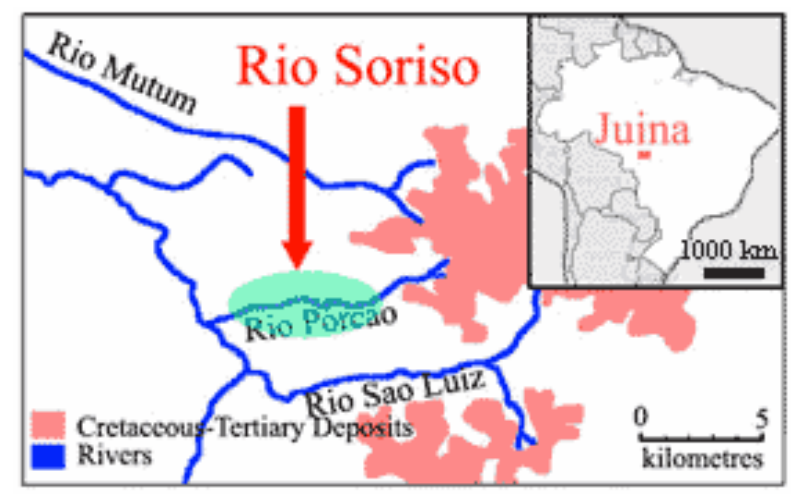

Fig.1. Location map for the Rio Soriso. Inset is a map of central South America. The Juina area is located in Southwestern Brazil.

\section{MORPHOLOGICAL STUDIES:}

The majority of examined diamonds are coloured, with the most commonly observed colours being: grey (20\%), yellow (13\%) brown (10\%) and non-uniform $(10 \%)$. Almost half of the diamonds studied (47\%) are colorless. Diamond crystal types include dodecahedral (42\%), combination octahedral-dodecahedral (13\%), octahedral (4\%) and less common forms such as

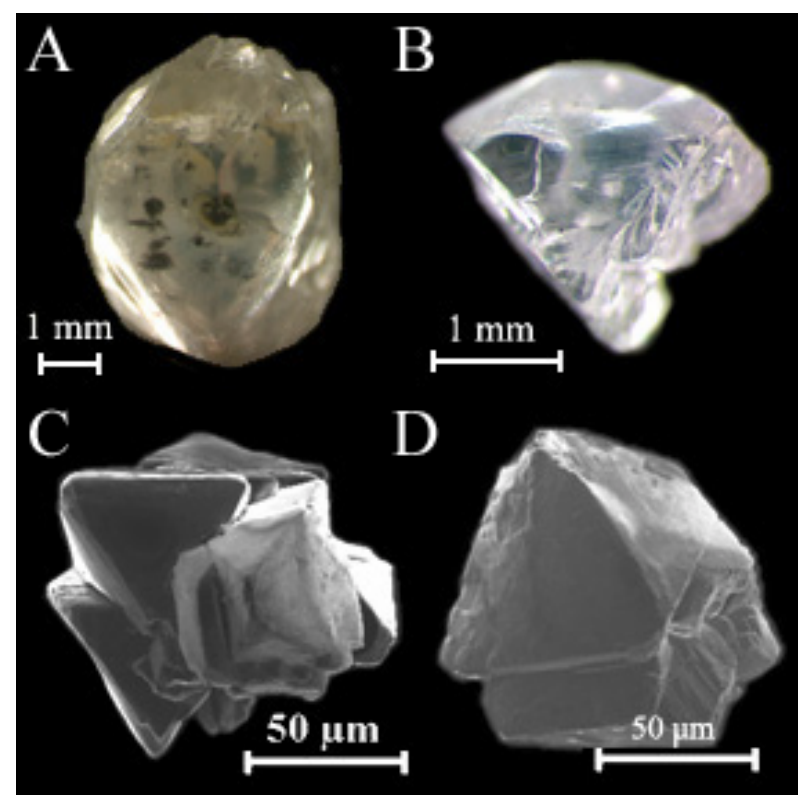

Fig.2. Some crystal forms of Rio Soriso diamonds. A) dodecahedroid, B) combination octahedral-dodecahedroid, C) aggregate and D) octahedral twin.

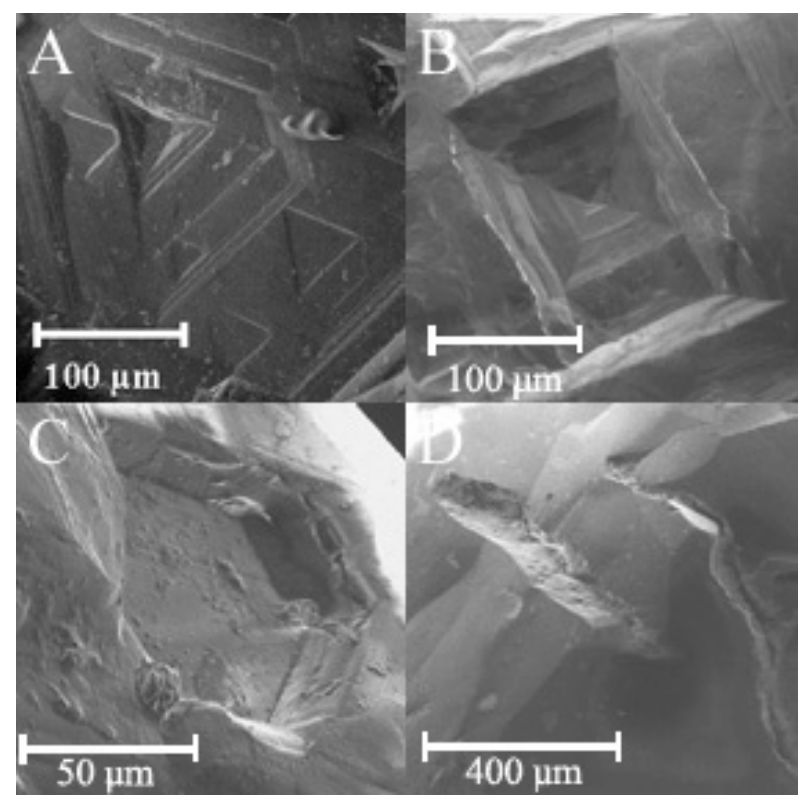

Fig.3. Some features produced by local chemical dissolution (etching) seen on Rio Soriso diamonds. A) trigons, B) quadrons, C) hexagons and D) etch channels. 


\section{NITROGEN STUDIES:}

cuboids and cubo-octahedral diamonds (Fig. 2). These crystal types also form aggregates (7\%) and twins $(1.4 \%)$. Twenty-nine percent of the crystals examined are fragments and could not be classified. The degree of resorption for each diamond was estimated using a semi-quantitative method introduced by Robinson et al. (1989) and further developed by McCallum et al. (1994). The proportion of growth faces on each crystal is compared to the proportion of resorbed faces. From these observations, each crystal is assigned to a resorption 'class', with class 6 indicating no resorption and class 1 indicating no growth faces. The average resorption class of the Rio Soriso diamonds falls between class 2 and 3. Local etching is observed on the majority of stones in the form of trigonal, hexagonal, and tetragonal pits as well as in the form of etch channels (Fig. 3). Deformation laminations are observed on $20 \%$ of the diamonds (Fig. 4). These lamination lines indicate that the diamonds were plastically deformed in the mantle and are considered the cause for brown and pink colouration in diamond (Harris, 1987). A disproportionate number of brown and pink diamonds in this study indeed possess these laminations.

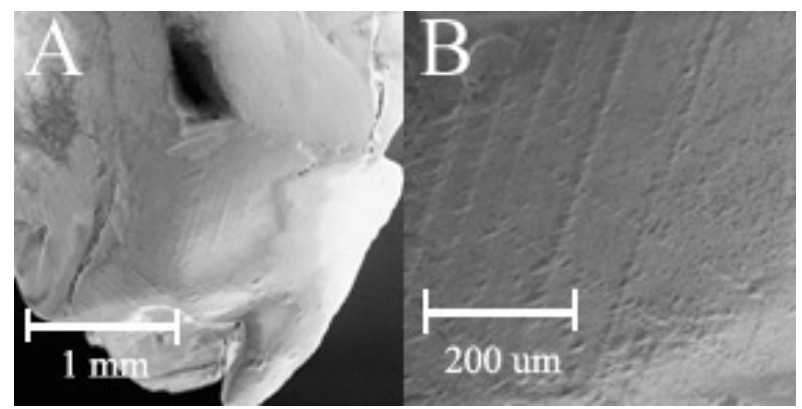

Fig.4. Deformation laminations on the Rio Soriso diamonds in macroscopic (A) and microscopic view (B).

Two characteristics of the Rio Soriso suite have direct relevance to local diamond exploration. The diamonds lack brown and green pigmentation spots which are the product of radiation damage and commonly found on diamonds in Phanerozoic placers (Afanasiev et al., 2000). Their absence indicates that the diamonds have not resided in a secondary Phanerozoic collector, such as the local Cretaceous-Tertiary "Chapada" deposits. Secondly, it is not likely that the diamonds have travelled far from their source as suggested by the unabraded conchoidal fracture surfaces and the general paucity of mechanical abrasion marks.
Nitrogen aggregation and concentration in diamond were measured using a Nicolet Fourier Transform Infrared (IR) spectrometer. IR spectra in the onephonon region between $900-1500 \mathrm{~cm}^{-1}$ were then deconvoluted into three separate curves that are attributed to A centers (pairs of N), B centers (likely four nitrogen atoms tetrahedrally arranged about a vacancy), and D centres (likely due to the formation of carbon platelets). Total nitrogen concentrations in crystals examined are low, ranging from 0 to $367 \mathrm{ppm}$ with a mean of $67 \mathrm{ppm}$ and mode of $42 \mathrm{ppm}$. $23 \%$ of the diamonds contain less than 20 ppm nitrogen and are considered type IIa while the remainder $(77 \%)$ fall into the type Ia category. $66 \%$ of the diamonds contain aggregated nitrogen in both $\mathrm{A}$ and $\mathrm{B}$ centres and are further classified to type $\mathrm{IaAB}$ while the remaining $11 \%$ of diamonds have only $\mathrm{B}$ centres and are thus classified as type $\mathrm{IaB}$. The average ratio of $\mathrm{B} /(\mathrm{A}+\mathrm{B})$ centres, or aggregation state, for all diamonds is very high and equal to $81 \%$. D centres are observed in all diamonds. They are interpreted by Woods (1986) to have formed from displaced carbon atoms during the formation of $\mathrm{B}$ centres. There is no correlation between $\mathrm{D}$ and $\mathrm{B}$ centres, thus indicating that the diamonds are likely irregular by classification of Woods (1986). Degradation of platelets is common in diamonds with a high proportion of $\mathrm{B}$ centres, and the departure from regularity is thus likely an indication that many of the Rio Soriso diamonds contain abundant degraded platelets that have been replaced by crystal defects such as dislocation loops and voidites (Evans, 1992).

Nitrogen studies have proven useful for fingerprinting diamond populations from around the world (Kaminsky et al., 2001a). Figure 5 compares nitrogen aggregation and concentration of the Rio Soriso suite of diamonds with other suites from around the world. The high proportion of $\mathrm{B}$ centres and relatively low concentration of nitrogen restricts this suite in a unique field along with other Juina area diamonds. Previously examined Juina diamonds were found to host super-deep mineral inclusions and thus it has been proposed that the nitrogen characteristics may be typical of all super-deep Juina diamonds (Kaminsky et al., 2001a). The nitrogen character of the Rio Soriso diamonds indicates that they may also be super-deep in origin with initial crystallization beginning in either the lower mantle $(>670 \mathrm{~km})$ or transition zone $(>410 \mathrm{~km})$. Further studies of mineral inclusions in the Rio Soriso diamonds are needed to confirm this preliminary conclusion. Assuming that the diamonds resided in the mantle for $3 \mathrm{Ga}$ and that the process of nitrogen aggregation 
follows second-order kinetics (Evans, 1992), calculated time-averaged mantle residence temperatures for this suite would likely exceed $1240{ }^{\circ} \mathrm{C}$.

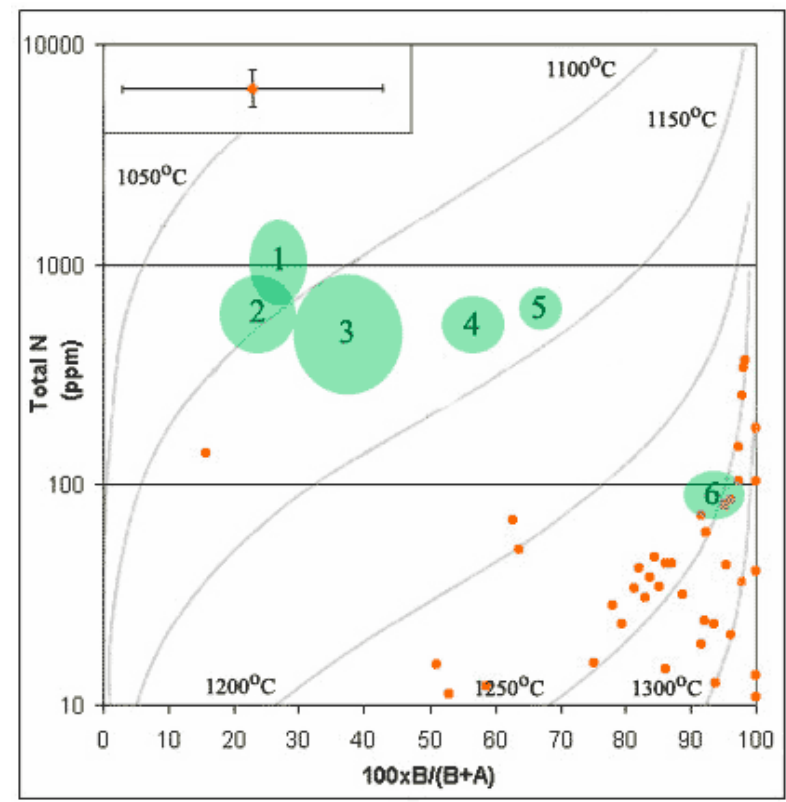

Fig.5. Nitrogen aggregation and concentration in Rio Soriso diamonds compared with similar data of other diamond suites (after Kaminsky et al., 2001a). Orange circles are individual data points for the Rio Soriso diamonds. Light green circles are population averages for diamonds from: 1) Arkhangelsk, 2) Malo-Botuobinsk, 3) Urals, Daldyn-Alakit, DO-27 and Premier, 4) Coremandel, 5) Guaniamo, and 6) Juina (excluding Rio Soriso). Isotherms represent time-averaged mantle residence temperatures for diamonds $3 \mathrm{Ga}$ in age. Error bar reflects $20 \%$ experimental error inherent to IR spectroscopy and data reduction and deconvoultion (Kaminsky et al., 2001a).

\section{FLUORESCENCE STUDIES:}

Under ultraviolet (UV) light, diamonds exhibit a range of fluorescence colours and intensities (Fig. 6). Colours observed are: blue (80\%), turquoise (14\%), green $(3 \%)$, and brown (1.5\%). $1.5 \%$ of diamonds are nonfluorescent. There is a positive correlation between fluorescence intensity and nitrogen concentration, and a negative correlation between fluorescence intensity and relative platelet concentration. There does not appear to be any relationship between nitrogen aggregation state and fluorescence intensity. No correlations were noted between fluorescence colours and nitrogen content. Nitrogen concentration, aggregation state, and relative platelet concentration values for turquoise fluorescent stones are intermediate between those for blue and green stones. It is postulated that green and blue stones represent end-members with respect to some particular defect or impurity and that turquoise fluorescent crystals contains elements of both endmembers.

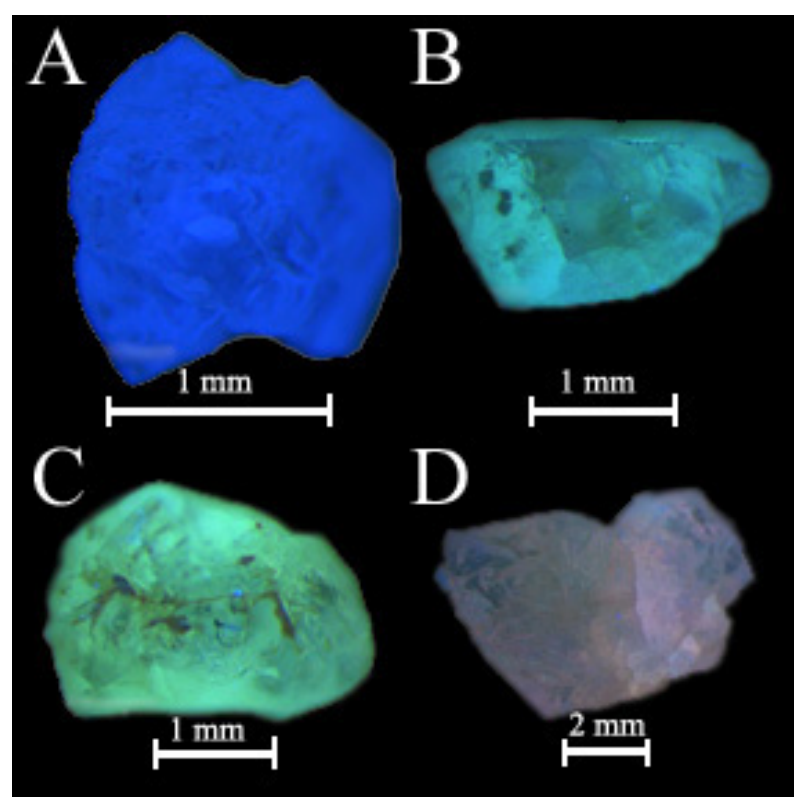

Fig.6. Various fluorescence colours of Rio Soriso diamonds: A) blue, B) turquoise, C) green, and D) brown. A 100 Watt UV bulb was used as a light source with photograph exposure times of 30 seconds.

\section{Crystal Growth Studies:}

Several diamonds were selected for detailed analysis and were made into plates by cutting two parallel surfaces with one passing through the centre of the crystal. Cathodoluminescence (CL) and IR studies have been performed on these plates. CL studies reveal that some diamonds display multiple stages of octahedral growth (an indicator of equilibrium conditions during crystallization) and resorption (Fig. 7A) and complex growth patterns (Fig.7B). Variation in nitrogen content and aggregation and relative platelet and hydrogen concentration has been analyzed from core to rim on two diamonds (Fig.7). Analysis of these two diamonds indicates that: i) nitrogen and hydrogen concentrations decrease from core to rim, ii) relative platelet concentration decreases from core to rim in one diamond (Fig. 7B), but shows no obvious trend in the other crystal (Fig. 7A), and iii) there is no obvious trend for nitrogen aggregation state. Studies on Yakutian diamonds by Bulanova (1995) found that B centres and hydrogen and platelet concentrations tend to decrease from diamond core to rim. Differences between these studies probably reflect different internal structures of the diamonds studied. 

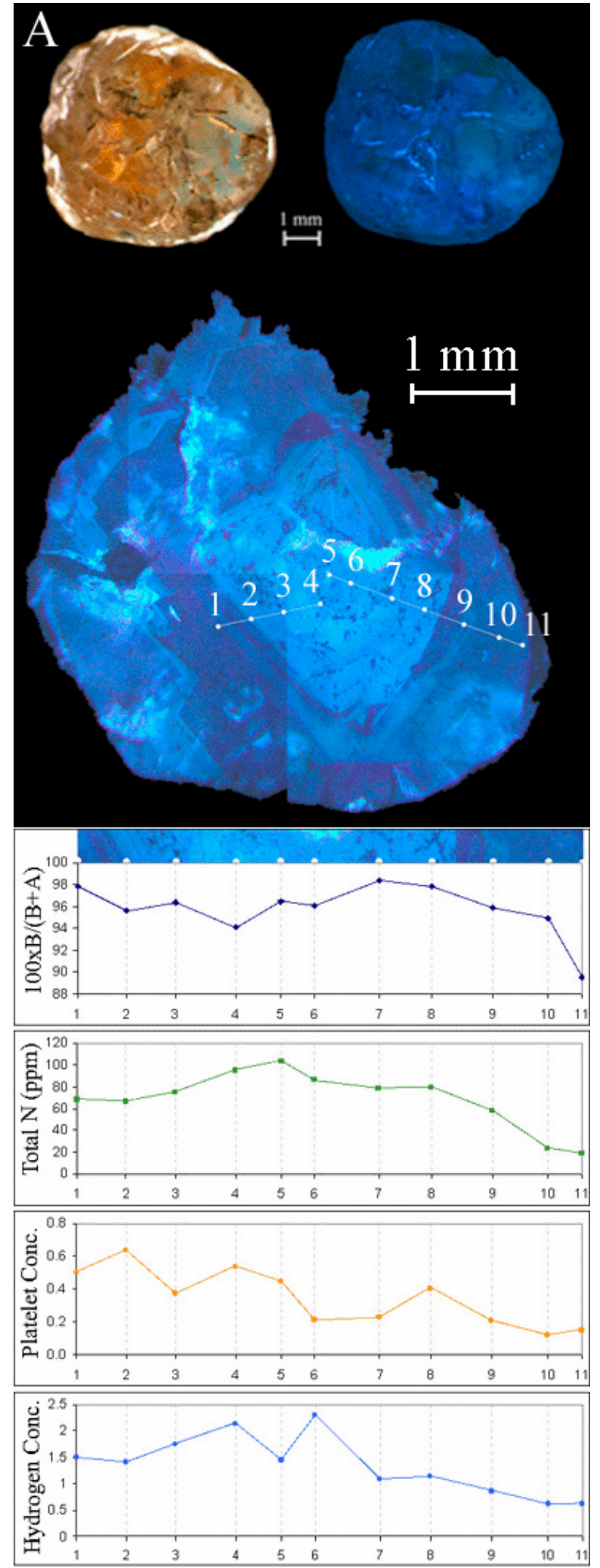

Fig.7. Microphotographs and chemical variation plots across diamond plates for samples \#3.1 (A) and \#1.4 (B). Plain light photos of the diamond, UV-induced luminescence and CL-induced luminescence are shown above. Note that A)
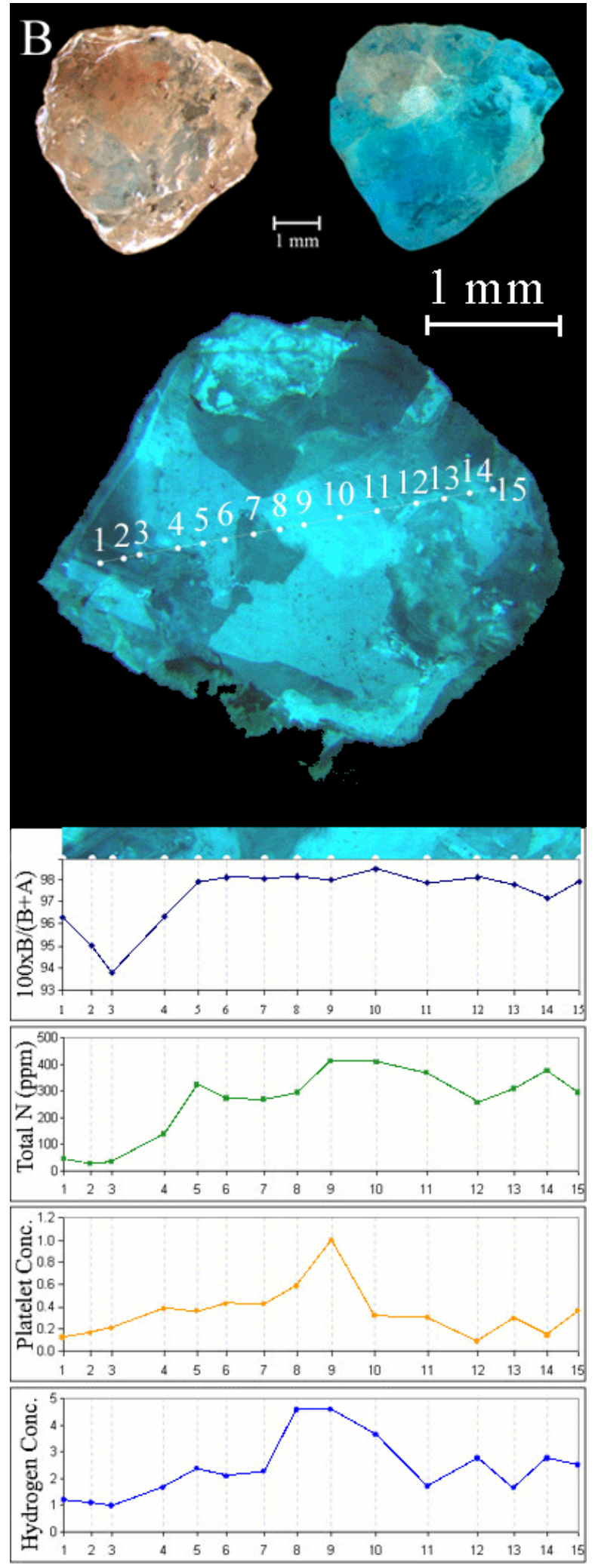

exhibits octahedral growth and resorption while B) exhibits a complex internal growth pattern. Chemical variation plots for data points, from top to bottom, are: aggregation state, total nitrogen concentration, relative platelet concentration, and relative hydrogen concentration. 
Visual observation indicates that nitrogen concentration is linked with CL intensity. This trend is best seen in figure $7 \mathrm{~B}$, where sectors with low $\mathrm{CL}$ intensity also contain lower amounts of total nitrogen.

Comparison of CL (electron-induced luminescence) and fluorescence (UV-wavelength induced luminescence) indicates that these two studies reveal similar patterns and are likely controlled by the same diamond characteristics (Fig. 7). Both CL and fluorescence demonstrate that induced luminescence intensity is related to nitrogen concentration but not aggregation state. Further examination of relative platelet concentrations and induced luminescence intensities reveal that there is a positive correlation in one diamond (figure 7B), a negative correlation for the population as a whole, and no obvious correlation in another diamond (figure 7A). The complex nature of platelet formation, aggregation, and subsequent degradation are possible factors responsible for this.

\section{REFERENCES}

Afanasiev, V.P., Yefimova, E.S., Zinchuk, N.N., and Koptil, V.T., (2000). Atlas of morphology of diamonds from Russian sources. Alrosa, Russia.

Bulanova (1995). The formation of diamond. Journal of Geochemical Research, 53: 1-23.

Evans, (1992). Aggregation of nitrogen in diamond. In: Field, J.E., (Ed.), The properties of natural and synthetic diamond. Academic Press, London, pp. 259-290.

Harris, (1987). Recent physical, chemical, and isotopic research of diamond. In: Nixon, P.H. (ed.), Mantle Xenoliths. John Wiley and Sons, Toronto, pp. 477-500.

Kaminsky, F.V., Khachatryan, G.K., (2001a). Characteristics of nitrogen and other impurities in diamond as revealed by infrared absorption data. The Canadian Mineralogist, 39, 1733-1745.

Kaminsky, F.V., Zakharchenko, O.D., Griffin, W.L., Channer, D.M., Khachatryan-Blinova, G.K. and Shiryaev, A.A. (2001b). Superdeep diamonds from the Juina area, Mato Grosso, Brazil. Contributions to Mineral Petrology 140, 734-753.

McCallum, M.E., Huntley, P.M., Falk, R.W., \& Otter, M.L. (1994). Morphological, resorption and etch feature trends of diamonds from kimberlite populations within Colorado-Wyoming State Line District, USA. In: Meyer, H.O.A., and
Leonardos, O.H., (Eds.), Diamonds: Characterisation, Genesis and Exploration. GPRM Spec. Publ. No 1/B, CPRM, Brasilia: 32-50.

Robinson, D.N., Scott, J.A., Van Niekerk, A., and Anderson, V.G. (1989). The sequence of events reflected in the diamonds of some southern African kimberlites. Kimberlite and Related Rocks, v.2. Geological Society of Australia Special Publication No. 14: 990-1000.

Woods, G.S., (1986). Platelets and the infrared absorption of type Ia diamonds. Proceedings of the Royal Society of London A 407, 219-238.

Contact: PC Hayman, University of British Columbia, 6339 Stores Road, Vancouver, BC, Canada, V6T 1Z4, E-mail: phayman@eos.ubc.ca 